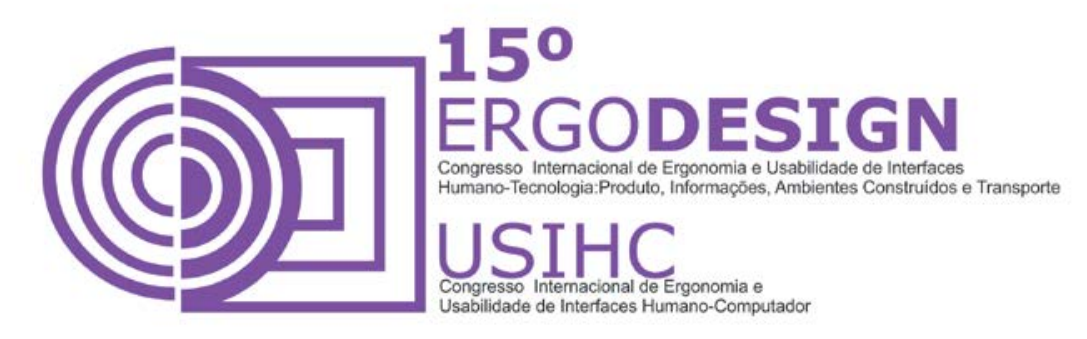

\title{
ANÁLISE ERGONÔMICA DA DESEMPENADEIRA - UM ESTUDO DE SUAS PRINCIPAIS FUNÇÕES E PROPOSTA PARA REDESIGN
}

\author{
ERGONOMIC ANALYSIS OF TROWEL - A STUDY OF THEIR \\ PRINCIAPAIS FUNCTIONS AND PROPOSAL FOR REDESIGN
}

\author{
SILVA, Anna Paula da (1); \\ SILVA, Tamires Maria de Lima (2); \\ CRISTINE, Mirelle (3)
}

(1) Universidade Federal de Pernambuco, Graduada em Design

e-mail:ap.x105@gmail.com

(2) Universidade Federal de Pernambuco, Graduada em Design

e-mail:tamiresdesigner@hotmail.com

(3) Universidade Federal de Pernambuco, Graduada em Design

e-mail:m.silva@brasil.br

\begin{abstract}
RESUMO
Um dos principais diferenciais num produto é a forma com que ele se adapta ao corpo humano proporcionando conforto ao usuário. Trabalhadores da construção civil foram observados em atividade, para eleição de um dos recorrentes instrumentos por eles utilizados, à desempenadeira, para estudo ergonômico e posterior proposta de redesign. Este estudo enfoca apenas possíveis resultados da intervenção ergonômica através de proposta de redesign, não foi realizado um estudo com protótipos ou um resultado final a ser lançado no mercado. As páginas seguintes conduzem uma análise desta ferramenta quanto a suas principais formas de uso e possíveis lesões por elas causadas.
\end{abstract}

Palavras-chaves: Ergonomia; Redesign; Desempenadeira.

\section{ABSTRACT}

One of the key differentiators in a product is the way it adapts to the human body providing comfort to the user. Construction workers were observed in activity, for the election of one of the recurring instruments used by them, the trowel, for ergonomic and later proposed redesign study. This study focuses only possible outcomes of ergonomic intervention through redesign proposal was not carried out a study with a 


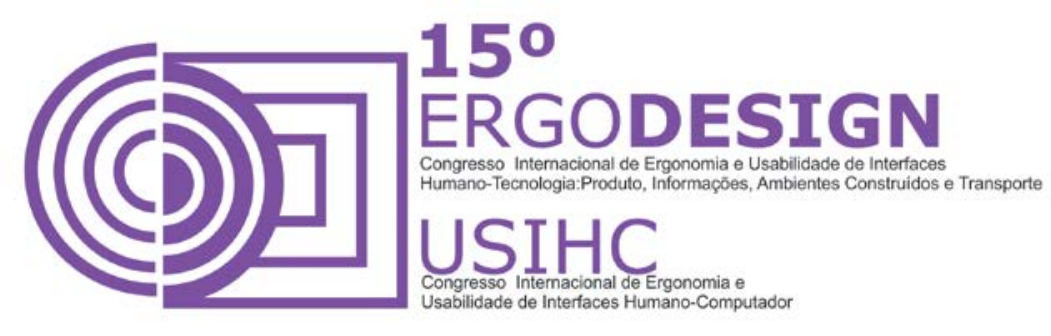

prototype or a final result to be launched on the market. The following pages conduct an analysis of this tool as their main forms of use and possible injuries caused by them.

Keywords: Ergonomics, Redesign; Trowel.

\title{
1. INTRODUÇÃO
}

O mercado está cada vez mais competitivo e uma das armas mais usadas como diferencial num produto é a forma com que ele se adapta ao corpo humano trazendo a quem for manuseálo maior conforto e menos lesões. Logo, a preocupação com a ergonomia na hora de projetar um produto, torna-se indispensável para um designer.

Este trabalho enfocou um instrumento indispensável na construção civil, a desempenadeira, usada por pedreiros para aplanar a argamassa já aplicada em determinada superfície, produzir sulcos nessa massa para melhor fixação de cerâmicas e pedras artesanais e realizar efeitos de textura nas paredes.

Por meio de um estudo de observação, manuseio da peça e entrevistas, pode-se notar alguns problemas em relação à postura adotada pelos trabalhadores, assim como na força exercida quando se utiliza a pega deste instrumento. Desse modo foi entendida a necessidade de uma intervenção ergonômica de forma que sua estrutura não comprometa a função principal de preparar uma determinada superfície. Ao observar, através de vídeos e fotos, os principais movimentos de usuários deste produto, foi visto a necessidade de transferir a força exercida no punho humano para o aparelho. Assim sendo, este trabalho apresenta uma possível solução de redesign da peça.

\section{CONTEXTUALIZAÇÃO ERGONÔMICA}

Procurando usar um conceito de design universal para ser aplicado a qualquer peça desenvolvida para atender e/ou facilitar alguma necessidade do homem. Levaram-se em consideração os princípios de Null (1993):

\begin{abstract}
"Uso equitativo - O produto deve ter dimensões, ajustes e acessórios que permitam atender ao maior número possível de usuários [...] Flexibilidade no uso - O projeto deve acomodar uma ampla gama de habilidades e preferências individuais, de modo a: possibilitar o uso aos destros e canhotos; [...], por exemplo; Uso simples e intuitivo - O produto deve ser facilmente entendido, sem depender de conhecimentos especializados, problema de linguagem ou nível de atenção momentânea; [...] (Null ,1993 apud lida,2005)."
\end{abstract}

Nesta nuance, em Bonsiepe (2011), compreende-se o designer como o executor de processos que precedem dá teoria a pratica e, portanto um dos responsáveis pela correta configuração de um artefato que possa ampliar o alcance das capacidades humanas. É dever incontestável dos ergonomistas, contribuir para a organização de modo geral das tarefas, ao que tange ações para planejar, projetar e avaliar os ambientes e sistemas pensados em concordância com as necessidades e limitações dos indivíduos. 


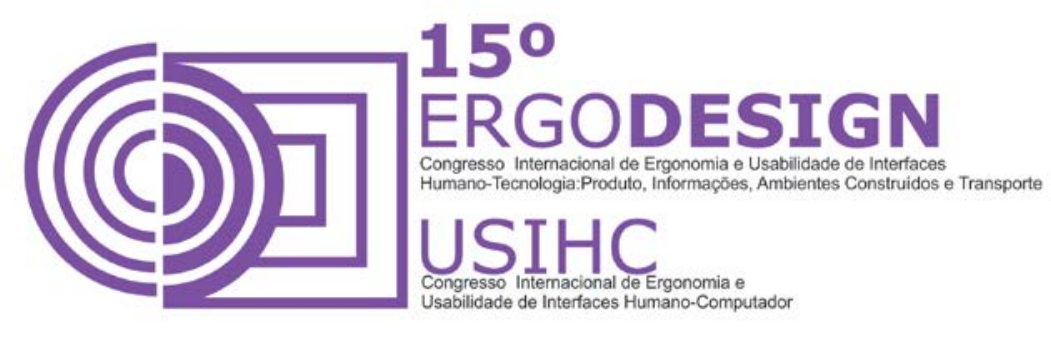

O presente trabalho compreende uma das classificações provenientes de estudos ergonômicos diretamente ligados ao homem, a ergonomia física, apresentada por Moraes e Mont'Alvão (2010), com base na Associação Internacional de Ergonomia (IEA - The International Ergonomics Association), apresentado pela Associação Brasileira de Ergonomia (ABERGO, 2007) a ergonomia física:

"[...] está relacionada com as características da anatomia humana, antropometria, fisiologia e biomecânica em sua relação à atividade física. Os tópicos relevantes incluem o estudo de postura no trabalho, manuseio de materiais, movimentos repetitivos distúrbios músculo - esqueletais relacionados ao trabalho, projeto de posto de trabalho, segurança e saúde." (MORAES E MONT'ALVÃO, 2010, p. 19)."

Assim sendo, despreocupação com fatores ergonômicos durante a configuração de um produto pode por sua vez ocasionar inúmeros transtornos ao usuário, sobremaneira quando este produto/artefato foi pensado para uso constante ou repetitivo. Entre as lesões e enfermidades que o trabalhador pode vir a sofrer, destacam-se a seguir àquelas diretamente relacionadas ao uso indevido de uma desempenadeira, por exemplo, artefato eleito para análise no presente artigo. Assim listadas conforme lida (2005):

- Síndrome do túnel do carpo: neuropatia resultante da compressão do nervo mediano no canal do carpo, estrutura anatômica que se localiza entre a mão e o antebraço.

- Distensão: lesão dos músculos e possivelmente também dos tendões, pode ser aguda, devido a pressão súbita; excessiva, em que as fibras musculares se rasgam, causando hemorragia, inchaço, dor e perda de força e de função; e lesão por fadiga, em que os músculos sofrem estiramento por serem submetidos a esforço crónico.

- Doença cervicobraquial: a irritação ou compressão de alguma das raízes nervosas provenientes da medula espinal na coluna cervical pode originar o aparecimento de uma dor intensa no pescoço, na região dorsal e num dos membros superiores.

- Deformação nas articulações: as lesões podem mesmo estender-se aos ossos, resultando na deformação da articulação.

- Artrose: doença reumática que incide principalmente nas articulações dos joelhos, coluna, quadril, mãos e dedos.

No mercado existem vários tipos de desempenadeira, cada uma com uma função diferenciada, porém todas têm em comum espalhar uma determinada massa para fim de uniformizar uma superfície. Os materiais usados para fabricação são: aço, madeira e plástico. Essa ferramenta, indispensável para a construção civil, desempenha algumas das funções listadas a seguir:

\subsection{Tipos e funções de desempenadeiras}

- Lisa: usada para acabamento e uniformização de cimento para reboco das paredes.

- Dentada: além de espalhar massas, é ideal para formar vincos na massa e assentamento de lajotas e azulejos. 


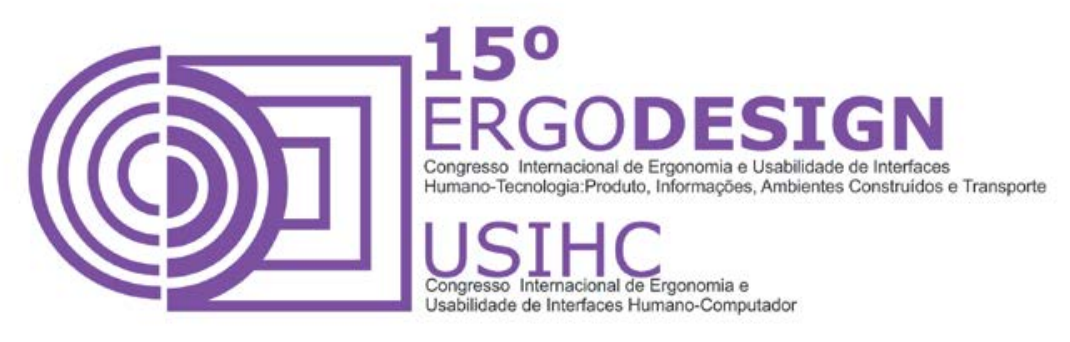

- De Rejunte: para aplicação em rejuntes de cimento, e remoção de excessos.

- Emborrachadas: para realizar acabamentos mais lisos em rebocos, substituindo o uso da esponja, assim como em aplicação de rejuntamento.

- Para Gesso: tem a função de alisar gesso, e também para aplicação do mesmo.

Este trabalho contém uma intervenção na DESEMPENADEIRA LISA METÁLICA, HASTE METÁLICA (figura 1), cujo foco está na sua pega, para facilitar o uso e reconfigurar à postura do trabalhador ao manuseá-la.

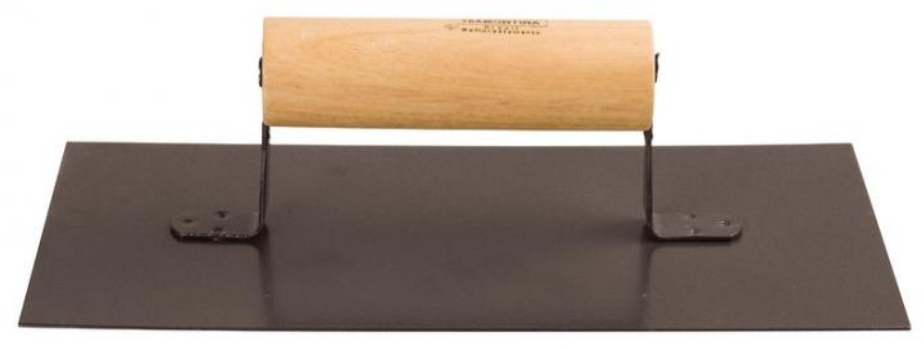

Figura 1 - Desempenadeira original - Fonte: acervo dos autores.

Especificações do modelo: Fabricante: Tramontina; Materiais: metal com cabo de madeira; Dimensões em mm (C.L.A.) 270x120x75; peso (kg) 0,32.

Para uma intervenção ergonômica neste produto deve-se levar em consideração que se trata de um instrumento utilizado em sua maioria por homens e que o custo beneficio para o usuário deve ser baixo, por se tratar de um utensílio de baixa complexidade e custo, já aplicado no mercado, não se sabe exatamente há quanto tempo, mas pressupõe-se que desde os primórdios da construção civil. Mediante a análise que se segue, serão propostas melhorias na configuração da desempenadeira supracitada, principalmente em relação a sua pega, levandose em consideração seu uso constante.

\section{ANÁLISE DE MOVIMENTOS}

Foram observados por meio de vídeos, os principais movimentos feitos pelo usuário ao trabalhar com uma desempenadeira. Desses movimentos destacam-se:

Tabela 1: Análise do Quadrante Inferior

\begin{tabular}{|l|l|l|l|}
\hline & Movimento & Pega & Postura \\
\hline
\end{tabular}




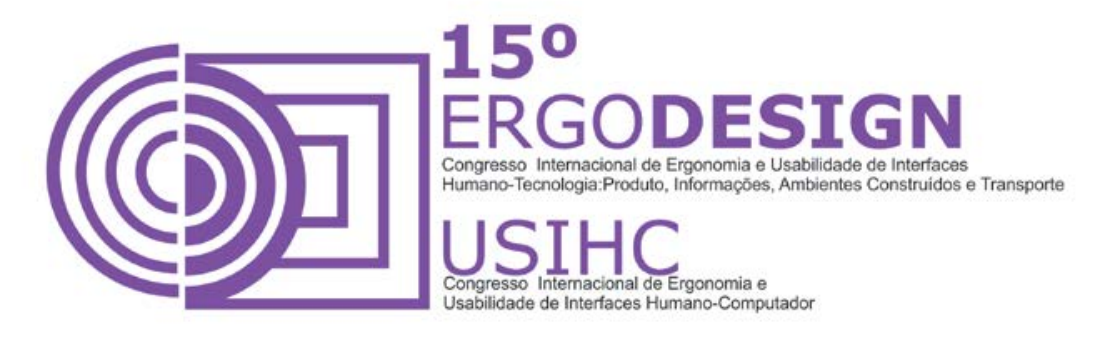

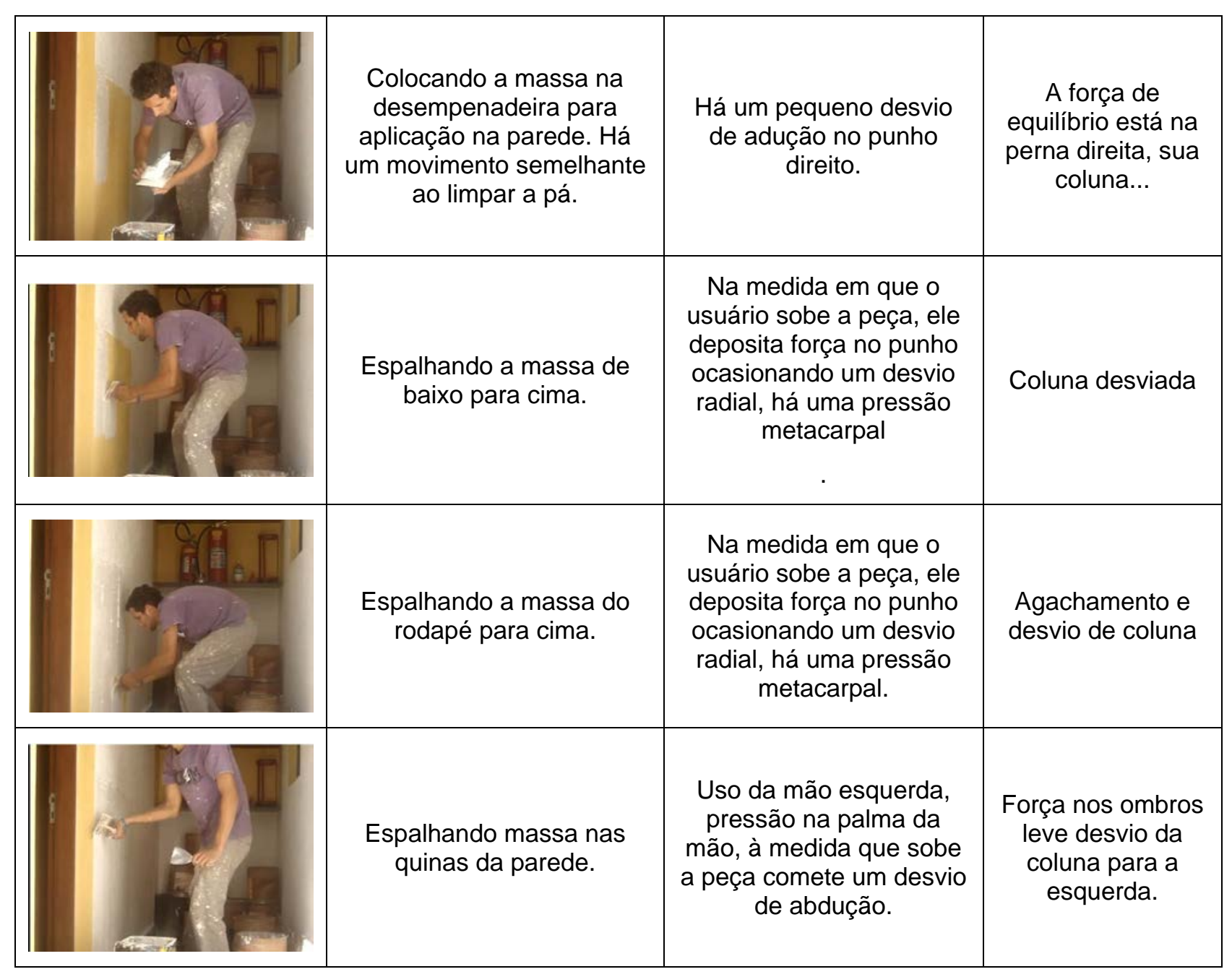

Fonte: vídeo - Aplicando textura na parede, disponível em: https://www.youtube.com/watch?v=1TaDzD3-054

Tabela 2: Análise do Quadrante Superior

\begin{tabular}{|l|l|l|l|}
\hline & Movimento & Pega & Postura \\
\hline
\end{tabular}




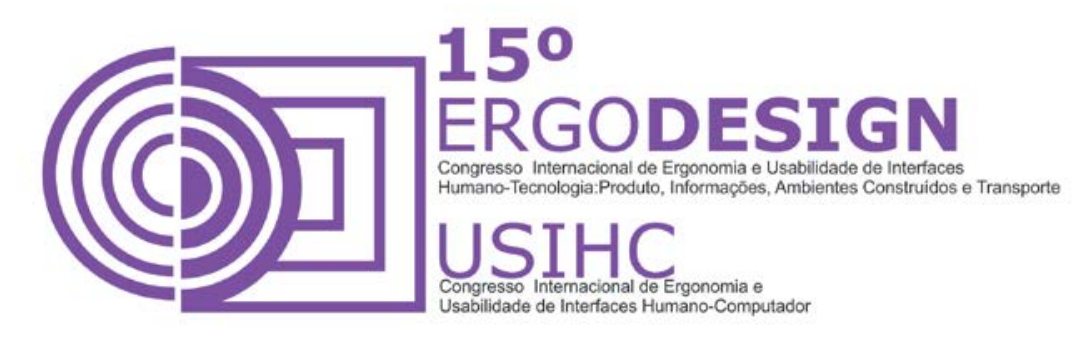

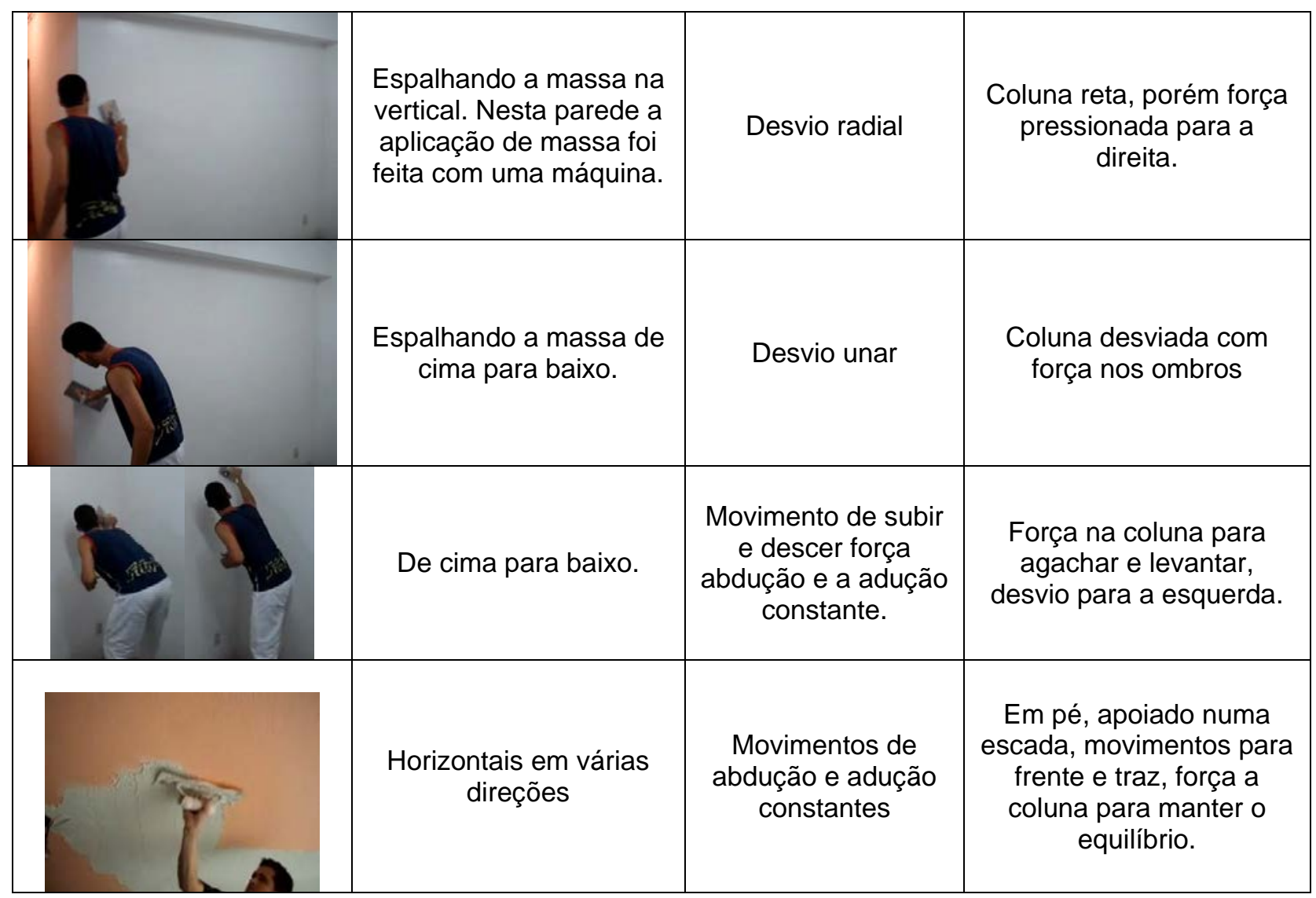

Fonte: vídeo - Projeção de Massa e Pintura Airless, disponível em: https://www.youtube.com/watch?v=u vsYXkXkw8\&feature=related

Tabela 3: Análise da aplicação de cimento no chão

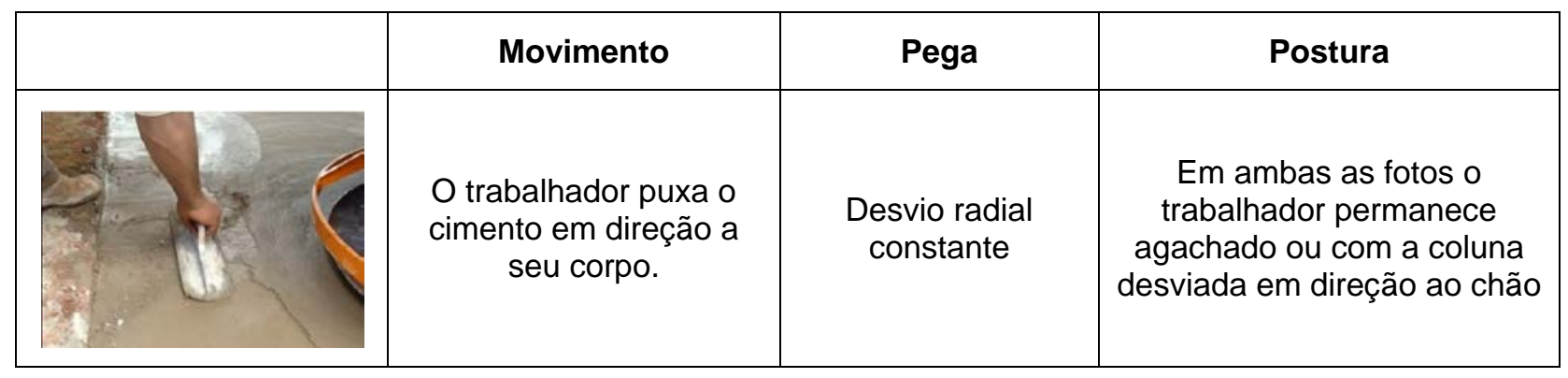



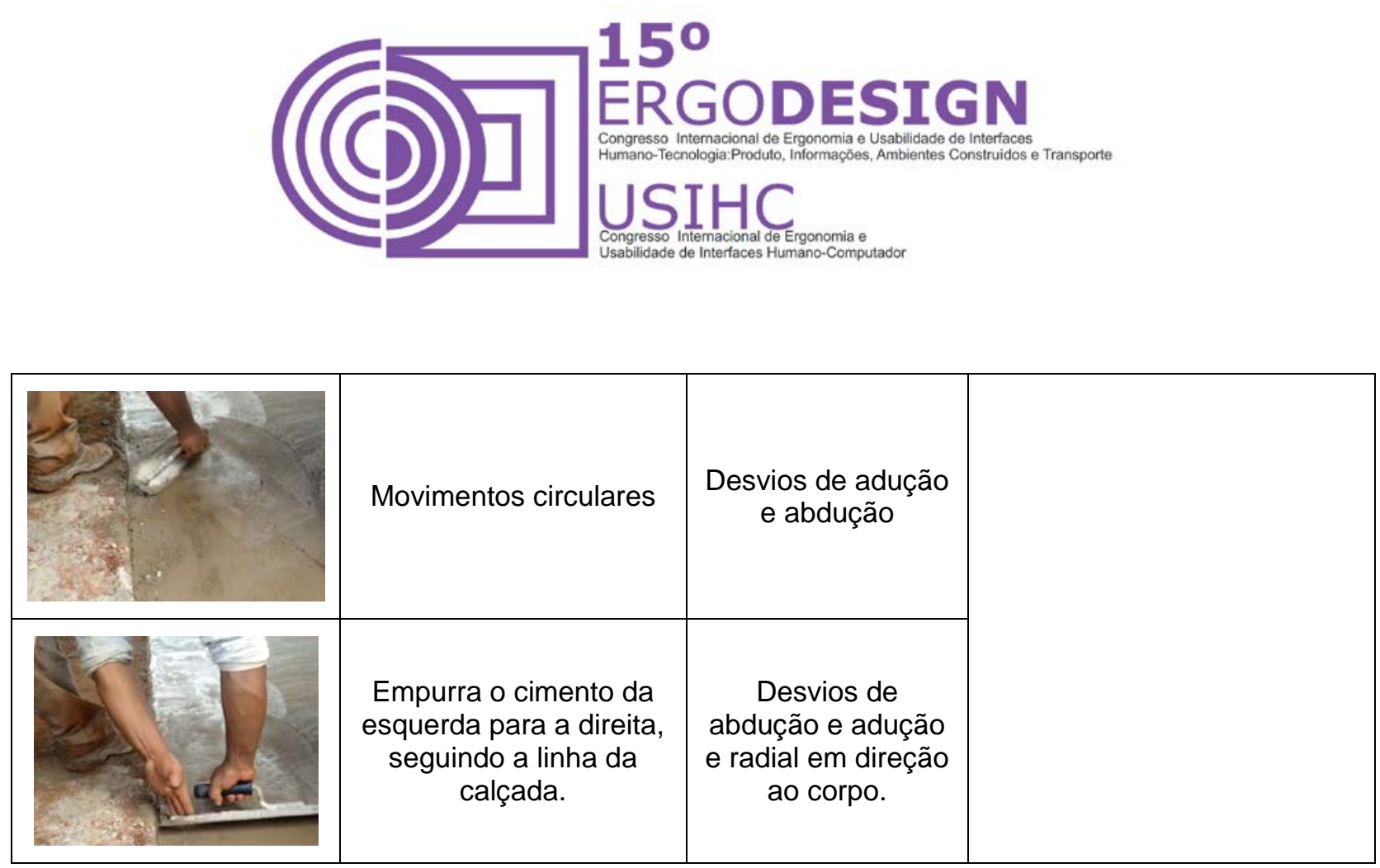

Fonte: vídeo - Desempenadeira Manual Finiti, disponível em:

https://www.youtube.com/watch?v=Bps4gzfxHtQ

\section{RESULTADO DA ANÁLISE DE MOVIMENTOS:}

Tabela 4: Quadro de problemas

\begin{tabular}{|l|l|l|l|}
\hline Problema & Causas & Sintomas & Solução Ergonômica \\
\hline Bolhas e Calosidades & $\begin{array}{l}\text { Atrito constante, } \\
\text { pressão em um ponto } \\
\text { (punho). }\end{array}$ & $\begin{array}{l}\text { Formação de líquido } \\
\text { subcutâneo ou } \\
\text { camadas secas e } \\
\text { densas na pele. }\end{array}$ & $\begin{array}{l}\text { Distribuição da carga sobre } \\
\text { uma superfície maior da } \\
\text { pele. }\end{array}$ \\
\hline $\begin{array}{l}\text { Síndrome do túnel do } \\
\text { carpo }\end{array}$ & $\begin{array}{l}\text { Pressão repetitiva e } \\
\text { stress sobre tendões. }\end{array}$ & $\begin{array}{l}\text { Dor, formigamento, } \\
\text { inchaço e insensibili- } \\
\text { dade. }\end{array}$ & $\begin{array}{l}\text { Ferramentas que possam ser } \\
\text { utilizadas na posição neutra. }\end{array}$ \\
\hline Distensão & $\begin{array}{l}\text { Stress excessivo } \\
\text { causado pela } \\
\text { combinação de força } \\
\text { e má postura. }\end{array}$ & $\begin{array}{l}\text { Dor e deslocamento } \\
\text { do membro. }\end{array}$ & $\begin{array}{l}\text { Reduzir a necessidade de } \\
\text { movimento brusco. }\end{array}$ \\
\hline $\begin{array}{l}\text { Distensão/Compressão } \\
\text { do nervo mediano }\end{array}$ & $\begin{array}{l}\text { Esforço com a mão } \\
\text { estendida ou } \\
\text { comprimida com } \\
\text { relação ao punho. }\end{array}$ & $\begin{array}{l}\text { Dor, insensibilidade } \\
\text { na mão, dor no } \\
\text { braço. }\end{array}$ & $\begin{array}{l}\text { Reduzir a pressão sobre o } \\
\text { nervo medial na área do } \\
\text { túnel carpal. }\end{array}$ \\
\hline $\begin{array}{l}\text { Doença } \\
\text { cervicobraquial }\end{array}$ & $\begin{array}{l}\text { Irritação ou } \\
\text { compressão das } \\
\text { raízes nervosas } \\
\text { provenientes da }\end{array}$ & $\begin{array}{l}\text { Compressão dos } \\
\text { nervos e vasos } \\
\text { sanguíneos entre o } \\
\text { pescoço e os }\end{array}$ & $\begin{array}{l}\text { Evitar posturas que } \\
\text { requeiram frequentes } \\
\text { alcances acima do nível dos } \\
\text { ombros. }\end{array}$ \\
\hline
\end{tabular}




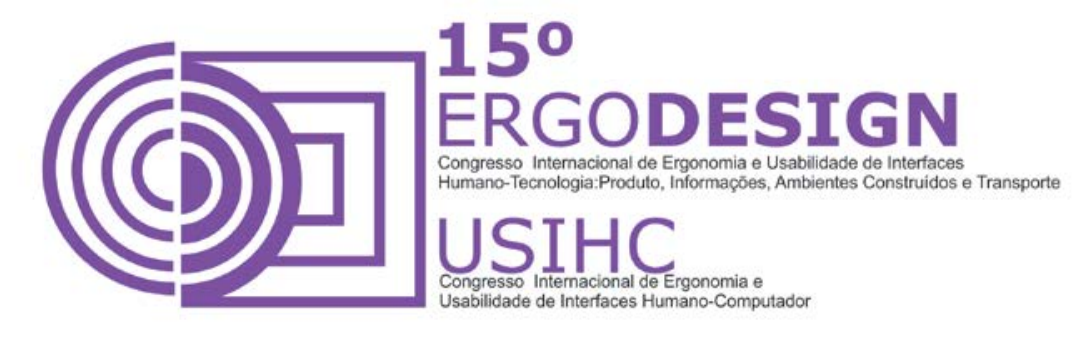

\begin{tabular}{|l|l|l|l|}
\hline & $\begin{array}{l}\text { medula espinal na } \\
\text { coluna. }\end{array}$ & ombros. & \\
\hline $\begin{array}{l}\text { Deformação nas } \\
\text { articulações }\end{array}$ & $\begin{array}{l}\text { Repetição de uma } \\
\text { atividade estressante } \\
\text { por longo tempo. }\end{array}$ & $\begin{array}{l}\text { Flexibilidade } \\
\text { reduzida, dor } \\
\text { contínua. }\end{array}$ & $\begin{array}{l}\text { Ferramenta que possa ser } \\
\text { usada em posição de } \\
\text { conforto durante a pressão. }\end{array}$ \\
\hline Artrose & $\begin{array}{l}\text { Frequente uso dos } \\
\text { membros em } \\
\text { posições extremas. }\end{array}$ & $\begin{array}{l}\text { Degeneração das } \\
\text { juntas, redução da } \\
\text { flexibilidade, rigidez. }\end{array}$ & $\begin{array}{l}\text { Reduzir forças, melhorar } \\
\text { postura. }\end{array}$ \\
\hline
\end{tabular}

Fonte: acervo dos autores

\section{METODOLOGIA}

A ação demandante desse trabalho teve início a partir da solicitação de atividade realizada durante $01^{\circ}$ semestre de 2011, na disciplina denominada Design e ergonomia e ministrada pelo docente Bruno Barros no Campus II da Universidade Federal de Pernambuco.

Utilizou-se de pesquisa de referencias para elencar os instrumentos similares passíveis de comparação e inspiração mediante o objeto de estudo, a desempenadeira. Conforme Vergara (2003), possibilitando a abrangência e a sistematização do conteúdo estudado em fontes diversas, entre elas: livros, revistas, e-books, e demais publicações digitais.

Como abordagem principal, os autores baseiam-se no método indutivo, e o raciocínio da pesquisa estruturou-se através da análise de conclusões particulares referentes às informações coletadas durante o levantamento de dados pertinentes aos vários formatos e condições de uso da desempenadeira, objetivando diretrizes de direcionamento para a geração de alternativas constantes no redesign. (FACHIN 2005). Os registros de uso do objeto em estudo foram possíveis através de vídeos de indivíduos em atividade assim como fotografias estratégicas de determinadas posições ocasionadas por seu manuseio e depoimentos concedidos através de entrevistas diretas. (MARCONI e LAKATOS, 2004).

\section{RESULTADOS}

Este estudo levou em consideração as angulações exercidas pelo punho a cada movimento estudado nos usuários da desempenadeira.

\subsection{Etapa de criação I: Estudando o punho humano}

A articulação do punho detém várias estruturas ósseas, responsáveis por conectar a mão ao antebraço por meio de tendões, músculos e ligamentos. É esta articulação que permite as mudanças de orientação da mão em relação ao antebraço e transmite as forças da mão ao antebraço e vice-versa (KAPANDJI, 2000 citado em ESTIVALENT, 2004). 


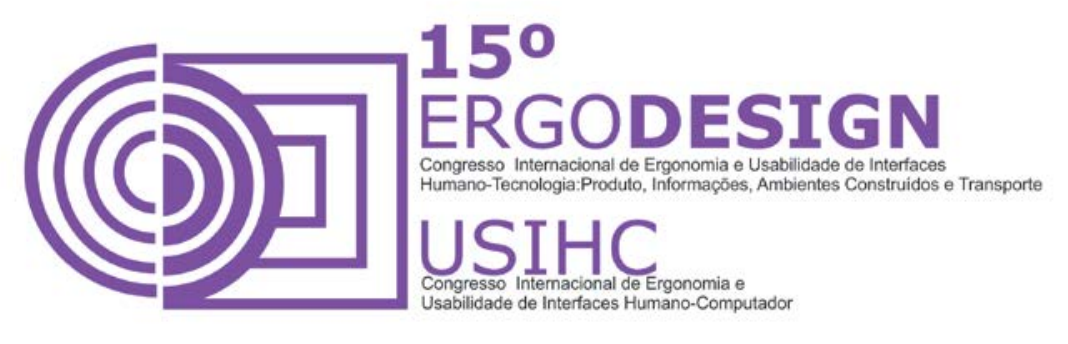

Por vezes o punho parece ter uma estrutura mole, mas através de seus movimentos é capaz, é capaz de exercer força sobre superfícies, como claramente na análise feita através da desempenadeira. Ele torna um instrumento reto e simples capaz de transformar uma superfície de massa relativamente lisa. Portanto, esse trabalho enfoca as angulações da mão e as estruturas musculares.

De acordo Palmer e Epler (2000), Marques (2003) e Magee (2002), citados em JOÃO (2005), a flexão do punho ocorre na articulação radiocárpica, no plano sagital nas articulações radiocárpicas e intercápicas, determina-se uma "Amplitude articular: $0^{\circ}-90^{\circ}$ e $0^{\circ}-80 / 90^{\circ}$ ". E que a extensão do punho ocorre numa amplitude articular de $0^{\circ}-70^{\circ}$ (Marques, 2003) $0^{\circ}-70 / 90^{\circ}$ (Magee, 2002) $0^{\circ}-90^{\circ}$ (Palmer \& Epler, 2000), como mostram respectivamente as figuras a seguir:
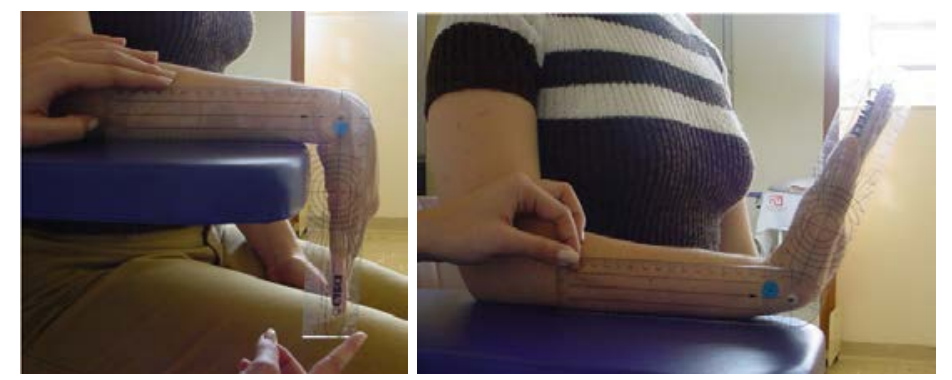

Figuras 2 e 3 - Goniometria - Flexão do Punho - Fonte: JOÃO, 2005.

\subsection{Proposta de redesign}

Entre as alternativas em destaque a desempenadeira passa agora a possuir de haste metálica, capaz de unir o mecanismo à pega, que passou a ser emborrachada para maior conforto do usuário. Sugere-se ainda que esta nova pega possua partes antiderrapantes, especialmente desenhadas de acordo com a mão do trabalhador.

O mecanismo funciona da seguinte forma: há uma liga de borracha presa na base de metal e no centro da esfera, que simula a estrutura muscular no punho humano, ela será responsável para que a pega sempre volte ao ângulo de $90^{\circ}$. A esfera fará os movimentos angulares para frente e para traz nos emassamentos horizontais, também a uma angulação especial para os movimentos na vertical. As dimensões de largura e profundidade permanecem as mesmas da antiga desempenadeira. Tudo de acordo com os estudos do movimento do punho que assegura que o usuário permanecerá com sua mão num ângulo natural de $90^{\circ}$ : 

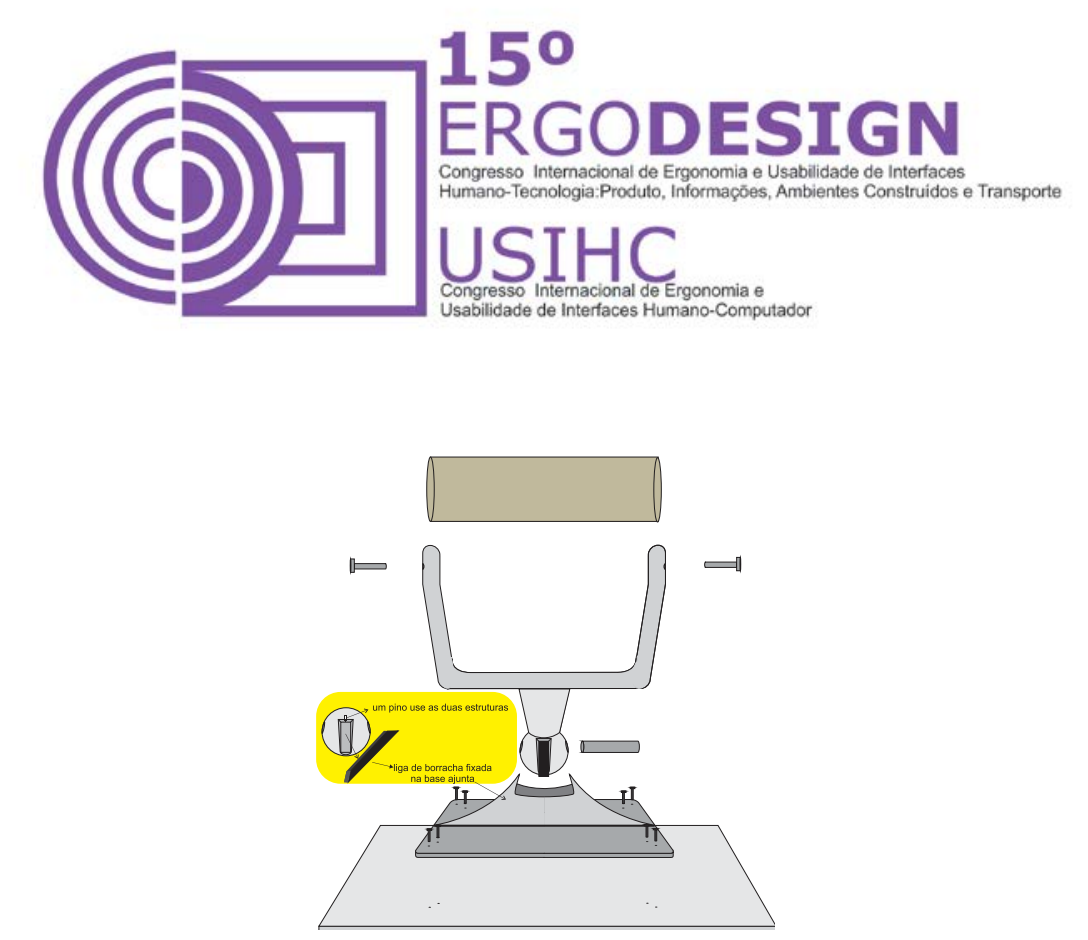

Figura 4: Vista explodida - Fonte: Acervo dos autores
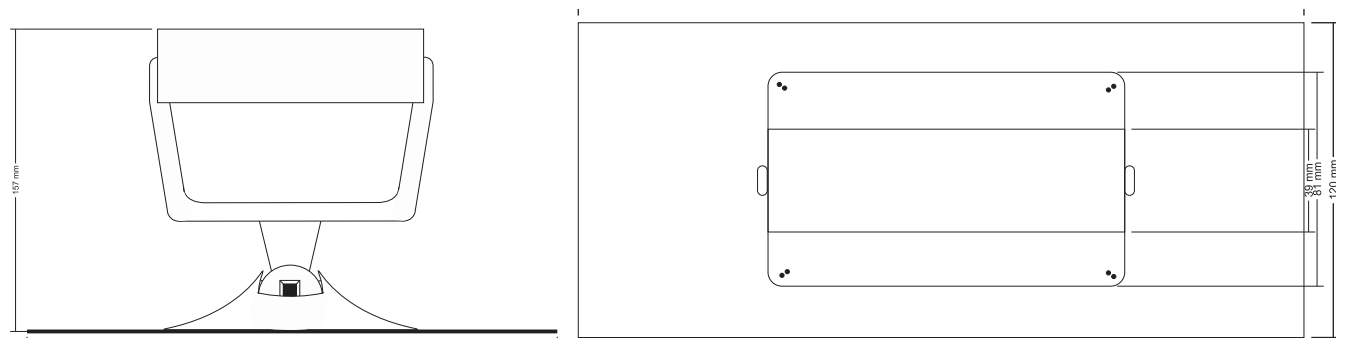

Figuras 5 e 6: Vista frontal e superior da nova pega - Fonte: Acervo dos autores.

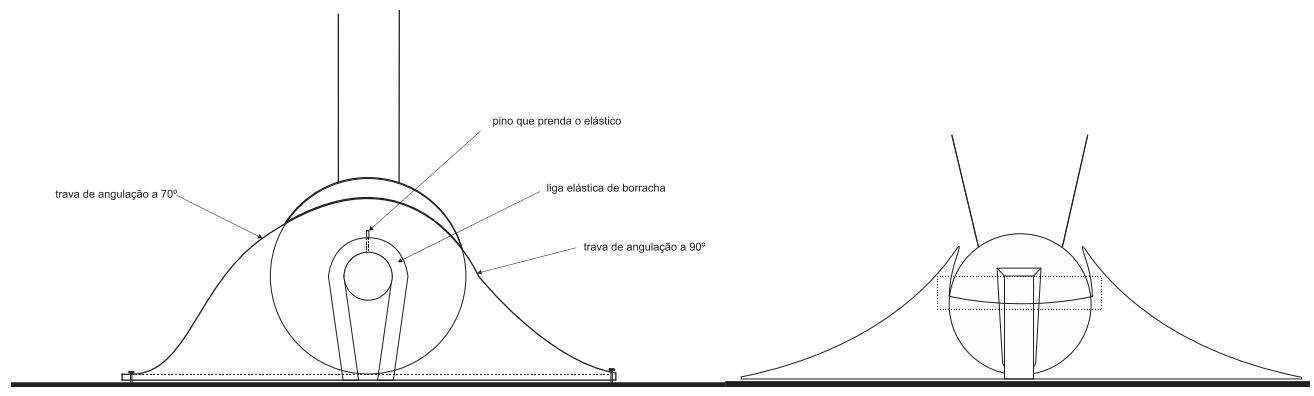

Figuras 7 e 8: Vistas lateral e frontal respectivamente - Fonte: Acervo dos autores.
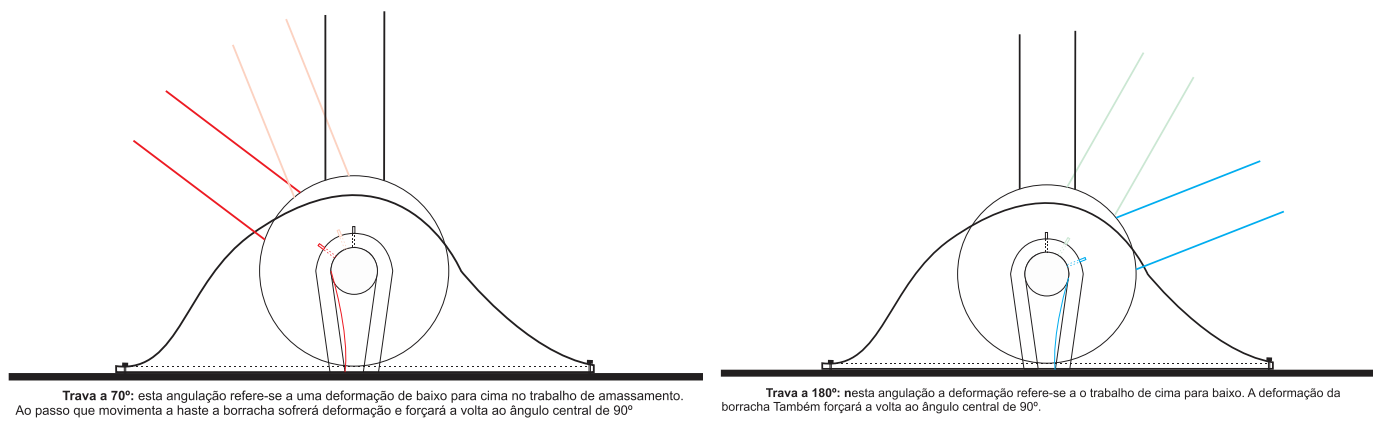

Figuras 9 e 10: Especificação de mecanismo - Fonte: Acervo dos autores. 

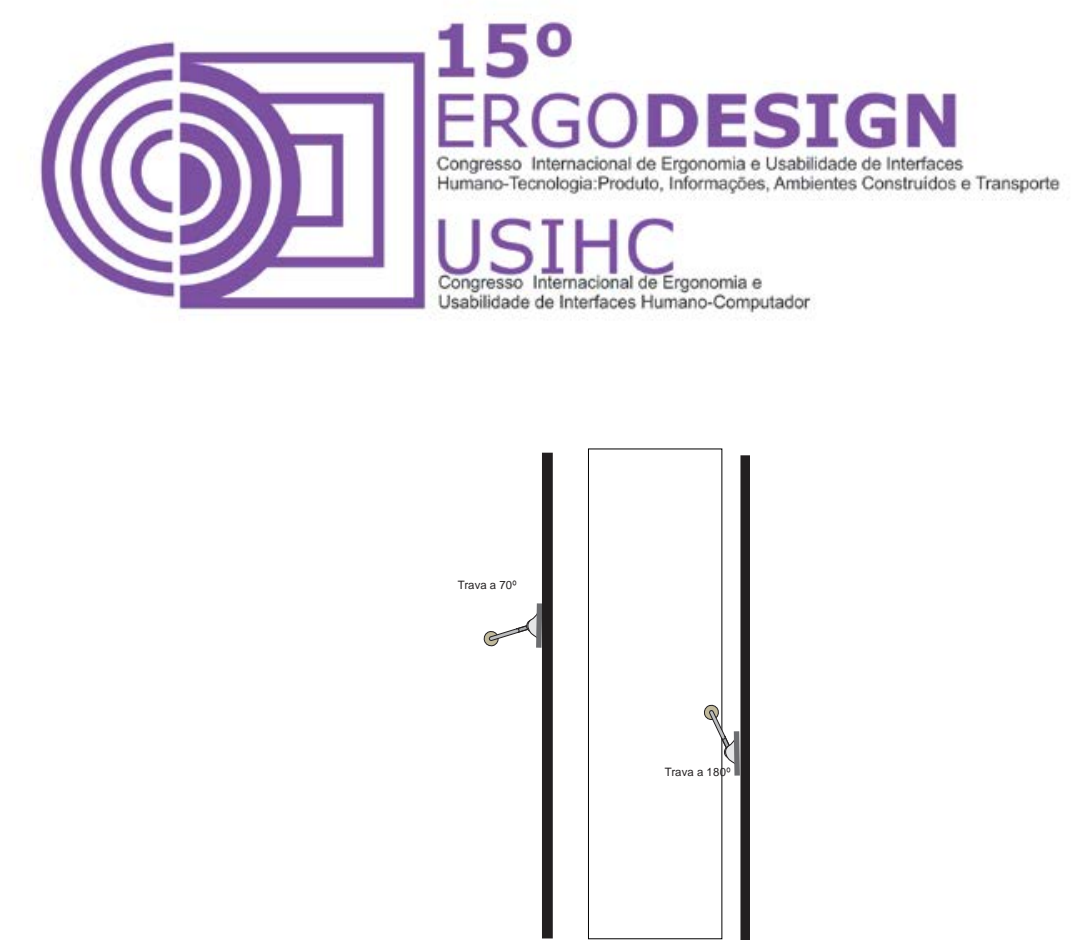

Figura 11: Especificações de uso, figura humana (o corpo permanece com suas posturas naturais, havendo leve inclinação nos movimentos horizontais). No primeiro quadro a trava a $70^{\circ}$ e no segundo a $180^{\circ}$ - Fonte: Acervo dos autores.

Tabela 5: Materiais necessários à configuração do redesign proposto

\begin{tabular}{|c|c|c|c|c|c|}
\hline Material & & & & & \\
\hline Especificação & $\begin{array}{l}\text { Placa de } \\
\text { aço inox. }\end{array}$ & $\begin{array}{l}\text { Bola de silicone } \\
\text { e Liga de } \\
\text { borracha. }\end{array}$ & Parafuso & Plástico & $\begin{array}{c}\text { Cone } \\
\text { de borracha } \\
\text { Kraton }\end{array}$ \\
\hline Função & $\begin{array}{c}\text { Evitar } \\
\text { oxidação. }\end{array}$ & $\begin{array}{l}\text { Rotacionar a } \\
\text { pega em } 90^{\circ} \text {. }\end{array}$ & $\begin{array}{c}\text { Unir e dar } \\
\text { sustentação às } \\
\text { peças. }\end{array}$ & $\begin{array}{l}\text { Revestimento } \\
\text { das peças. }\end{array}$ & $\begin{array}{c}\text { Para precisar a } \\
\text { pega. }\end{array}$ \\
\hline
\end{tabular}

Fonte: acervo dos autores.

\section{CONCLUSÕES}

Como já foi esclarecido no inicio deste trabalho, não foi realizado qualquer tipo de modelo do produto proposto no redesign, porém, para fim de pesquisas posteriores as considerações aqui descritas são de grande importância. No mercado não há nenhum produto deste tipo que seja de fato adaptável ao trabalhador da construção civil. O mecanismo adicionado nesta proposta promete um maior apoio para o emassamento e preparação de superfícies na construção, embora reconheça-se que para maior aproveitamento e sucesso do instrumento proposto, este necessita ser devidamente construído e testado mediante prototipagem.

Procurou-se tornar o aparelho o mais próximo do punho possível, para que um eventual desgaste seja transferido para a máquina e não para o trabalhador. A pega, por ser de borracha, mais flexível, procura se adaptar a qualquer mão humana, evitando calos. A estética remete à sensação de segurança e qualidade, sem muitos apelos visuais, tendo em vista um público alvo mais preocupado com a funcionalidade do produto. Por fim vale destacar a 


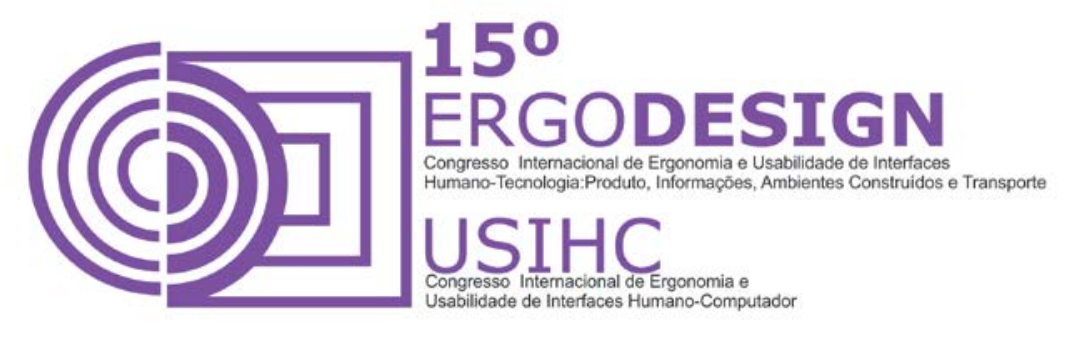

importância de estudos e pesquisas que aprofundem a possibilidade de redesign nesta ferramenta, indispensável para muitas ações na construção civil. Com as considerações aqui despostas procura-se impulsionar novos estudos e aperfeiçoamentos na desempenadeira, adaptando-os e complementando-os às funções descritas no referencial teórico.

\section{REFERÊNCIAS BIBLIOGRÁFICAS}

BONSIEPE, Gui. Design, Cultura e Sociedade. São Paulo, Blucher, 2011.

IIDA, Itiro. Ergonomia: projeto e produção. São Paulo: Edgard Blücher, 2005.

JOÃO ,Sílvia Maria Amado. Avaliação Fisioterapêutica do Punho e da Mão. In: Biomecanica online,2005.>>http://www2.fm.usp.br/fofito/fisio/pessoal/isabel/biomecanicaonline/articulacoes/p unho/PDF/avalmao.pdf $<<$.

ESTIVALET, Patrícia Steinner. Avaliação dos movimentos de punho e de mão na atividade decromagem de cilindros de uma empresa do Vale do Rio dos Sinos - RS. Porto Alegre: UFRGS, 2004. Dissertação (Mestrado Profissionalizante em Engenharia), Escola de Engenharia, Universidade Federal do Rio Grande do Sul, 2004.

FACHIN, O. Fundamentos da Metodologia. 5. ed. São Paulo, Saraiva, 2005.

MARCONI, Marina A.; LAKATOS, Eva M. Metodologia Científica. $4^{\mathrm{a}}$ ed. São Paulo: Atlas, 2004.

MORAES, Ana M. MONT'ALVÃO, Claudia. Ergonomia: Conceitos e aplicações. $4^{\mathrm{a}}$ ed. ampl. Rio de Janeiro: 2AB, 2009.

VERGARA, Sylvia C. Projetos e relatórios de pesquisa em administração. $4^{\mathrm{a}}$ ed. São Paulo, Atlas, 2003.

Vídeos:

Aplicando textura na parede, publicado em 03 de jun de 1010, disponível em:

>>https://www.youtube.com/watch?v=1TaDzD3-054<<.

Projeção de Massa e Pintura Airless, publicado em 07 de jun de 2011, disponível em:

>>https://www.youtube.com/watch?v=u vsYXkXkw8\&feature=related $<<$.

Desempenadeira Manual Finiti, puclicado em 01 de jun de 2012, disponível em: >> https://www.youtube.com/watch?v=Bps4gzfxHtQ $<<$ 